\title{
Structural Characterization and Regiochemical Differentiation of $\alpha$-Cyanoethylindole Isomers in the Gas Phase
}

\author{
Gianluca Giorgi and Fabio Ponticelli \\ Department of Chemistry, University of Siena, Siena, Italy
}

\begin{abstract}
Mass spectrometry and tandem mass spectrometry techniques have been used to study the gas phase ion chemistry of isomeric $\alpha$-cyanoethylindoles obtained by photochemical reactions. Both the fragmentation reactions occurring in the ion source, as well as metastable decompositions produced by the molecular and selected fragment ions, have allowed us to structurally characterize and differentiate each isomer from the others. The experiments, carried out also on deuterium labeled analogs, have shown the role exerted by the $\alpha$-cyanoethyl substituent and by its position at the indolic ring on gas phase reactions that resulted to be distinctive and selective for each isomer. Ab initio theoretical calculations have been used to evaluate the stability and chemico-physical properties of different ion structures. (J Am Soc Mass Spectrom 2005, 16, 397-405) (c) 2004 American Society for Mass Spectrometry
\end{abstract}

$\mathrm{T}$ The indole is an important heterocyclic system. A lot of biologically and pharmacologically interesting compounds contain this nucleus. As an example, the tryptophan, an essential amino acid, contains the indolic system.

Several members of the indole alkaloid family, such as flavopereirin and sempervirin, have shown antitumor activity [1]. The pharmacological activity of some indolic derivatives [2] has stimulated considerable interest in the synthesis of a large number of congeners [3].

The structural characterization and differentiation of heterocyclic isomers, and of indole derivatives in particular, is quite important as they can show different chemico-physical properties and activities. As the gas phase reactions occurring inside a mass spectrometer are strictly related to the structure of a compound, mass spectrometry (MS) and tandem mass spectrometry (MS/MS) are very powerful tools for isomeric characterization and differentiation. Their application in the field of heterocycles, and in particular in the characterization of the indole skeleton, has been successful [4-12].

In the frame of a research aimed at studying the gas phase ion chemistry of heterocycles [13-16], we wish to report here on a study devoted to the characterization and differentiation of a series of $\alpha$-cyanoethyl-3-methylindoles 1-4 and a $3 \mathrm{H}$-indole derivative 5 (Scheme 1) obtained by photochemical reactions [17].

All these compounds have the same formula and

Published online January 29, 2005

Address reprint requests to Dr. G. Giorgi, Department of Chemistry, University of Siena, via Aldo Moro, I-53100 Siena, Italy. E-mail: gianluca.giorgi@unisi.it molecular weight equal to $184 \mathrm{u}$. Compounds $\mathbf{1}-\mathbf{4}$ are regio isomers, differing in the position of the $\alpha$-cyanoethyl substituent on the heterocyclic system. They are also structural isomers of derivative 5 that has the $3 \mathrm{H}$-indole ring. The characterization and differentiation of Compounds 1-5, together with the study of analogs labeled at different positions, are interesting not only to evaluate the effect of the position of the substituent and of the nature of the indole ring on the gas phase decomposition pathways, but also to ascertain whether isomerization processes eventually occur.

Different mass spectrometry and tandem mass spectrometry techniques have been applied to the study of different ionic species produced in the gas phase by Isomers 1-5 and to evaluate their unimolecular reactivity. Metastable decompositions followed by the molecular ions and the most abundant fragment ions formed under electron ionisation have been selectively studied. The experimental approach is accompanied by theoretical ab initio molecular orbital calculations.

\section{Experimental}

Compounds 1-5 were synthesized by photochemical irradiation at $\lambda=253.7 \mathrm{~nm}$ of 3-methylindole (Fluka, Milan, Italy) and an excess of acrylonitrile (Aldrich, Milan, Italy) in methanol as previously reported [17]. Deuterium labeled derivatives were prepared by replacing methanol with $\mathrm{CD}_{3} \mathrm{OD}$ (Aldrich) or starting from 3-methylindole and $\mathrm{CD}_{2} \mathrm{CDCN}$ (Aldrich) in methanol following the same synthetic approach [17].

Mass spectrometric measurements were performed on a VG 70-250S (VG Analytical Ltd., Manchester, UK) two sector mass spectrometer with Nier-Johnson EB geometry coupled to an OPUS 2000 data system. Elec- 
<smiles>[R]c1cc([R3])c2c(C)c([R])n([R1])c2c1</smiles><smiles>[R]C1(C)C=Nc2ccccc21</smiles>

1. $\mathrm{R}_{1}=\mathrm{CH}(\mathrm{CN}) \mathrm{CH}_{3}$

$\mathrm{R}_{2}=\mathrm{R}_{3}=\mathrm{R}_{4}=\mathrm{H}$

5. $\mathrm{R}=\mathrm{CH}(\mathrm{CN}) \mathrm{CH}_{3}$

2. $\mathrm{R}_{2}=\mathrm{CH}(\mathrm{CN}) \mathrm{CH}_{3}$

$\mathrm{R}_{1}=\mathrm{R}_{3}=\mathrm{R}_{4}=\mathrm{H}$

3. $\mathrm{R}_{3}=\mathrm{CH}(\mathrm{CN}) \mathrm{CH}_{3}$

$\mathrm{R}_{1}=\mathrm{R}_{2}=\mathrm{R}_{4}=\mathrm{H}$

$3 d_{2} \cdot \mathrm{R}_{3}=\mathrm{CH}(\mathrm{CN}) \mathrm{CH}_{2} \mathrm{D}$

$\mathrm{R}_{1}=\mathrm{D} \quad \mathrm{R}_{2}=\mathrm{R}_{4}=\mathrm{H}$

4. $\mathrm{R}_{4}=\mathrm{CH}(\mathrm{CN}) \mathrm{CH}_{3}$

$\mathrm{R}_{1}=\mathrm{R}_{2}=\mathrm{R}_{3}=\mathrm{H}$

$\mathbf{n} d_{1} ; \mathrm{R}_{n}=\mathrm{CH}(\mathrm{CN}) \mathrm{CH}_{2} \mathrm{D}$

$\mathbf{n} d_{3} ; \mathrm{R}_{n}=\mathrm{CD}(\mathrm{CN}) \mathrm{CHD}_{2}$

Scheme 1

tron ionization was performed at $70 \mathrm{eV}$, emission current $0.2 \mathrm{~mA}$, with a source temperature of $200{ }^{\circ} \mathrm{C}$. The accelerating voltage was $8 \mathrm{kV}$ and the resolution was $1000 \mathrm{M} / \Delta \mathrm{M}$ (10\% valley). High resolution and accurate mass measurements were performed at resolution $10,000 \mathrm{M} / \Delta \mathrm{M}(10 \%$ valley) under the data system control against perfluorokerosene standard (Fluka). The samples were introduced in the EI source via the direct inlet without heating the probe.

Appropriate linked scans between the electrostatic and the magnet sectors were used to detect parent and product ions, and decompositions involving neutral losses in metastable ion processes. Even if the resolution in precursor ion selection is quite poor in $\mathrm{B} / \mathrm{E}$ experiments, in the present experiments it should be unitary given the low molecular weight (184 Da) of the isomers. Replicated measurements showed that the reproducibility of the relative peak abundances in metastable ion MS/MS spectra was within 10\%.

$\mathrm{Ab}$ initio molecular orbital calculations were performed on closed and open shell fragment ions by using the ${ }^{\circ}$ Gaussian ${ }^{\circ} 98^{\circ}$ package $[18]^{\circ}$ implemented ${ }^{\circ}{ }^{\circ}{ }^{\circ}{ }^{\circ}$ IBM ${ }^{\circ} S P$ RS/6000 Power 4 supercomputer at Cineca in Bologna (Italy). All geometries were fully optimized without any constraints $^{\circ}$ at $^{\circ}$ the ${ }^{\circ}$ Becke $^{\circ} 3 \mathrm{LYP}^{\circ}(\mathrm{B} \mathrm{LYP})^{\circ}[19]^{\circ}$ with ${ }^{\circ}$ the $6-31 G(d, p)$ level of theory. Each final lowest energy geometry was confirmed as a true minimum on the potential energy surface by normal-mode vibrational frequency calculation. For all the reported structures, only real frequencies were obtained. Zero-point energies and statistical thermodynamic properties at 298.15 $\mathrm{K}$ and 1 atm were calculated at the B3LYP 6-31G(d,p) level of theory.

\section{Results and Discussion}

\section{Mass Spectra}

Differently from positional isomers that often produce similar ${ }^{\circ} \operatorname{mass}^{\circ}$ spectra $^{\circ}[13],{ }^{\circ} \mathrm{Compounds}^{\circ} \mathbf{1}-\mathbf{5}$ give $^{\circ}$ rise $^{\circ}$ to fragmentation reactions in the ion source that result to be distinctive and regiospecific depending on the position of the $\alpha$-cyanoethyl substituent on the indolic ring. Most of the unimolecular reactions are the same for all the ${ }^{\circ}$ isomers ${ }^{\circ}\left(\right.$ Figure $^{\circ} 1^{\circ}$ and $^{\circ}$ Table $\left.^{\circ} 1\right)$, but $^{\circ}$ it ${ }^{\circ}$ is ${ }^{\circ}$ possible ${ }^{\circ}$ to differentiate each member on the basis of significant differences in the relative abundances of the product ions.

The molecular ions are abundant with relative intensities ranging from $60.5(\mathbf{2})$ to $100 \%(\mathbf{1}, \mathbf{3}, \mathbf{5})$, suggesting high $^{\circ}$ stability $^{\circ}$ in $^{\circ}$ the $^{\circ}$ gas $^{\circ}$ phase $^{\circ}\left(\right.$ Table $\left.^{\circ} 1\right) .^{\circ}$ The $^{\circ}$ loss $^{\circ}$ of

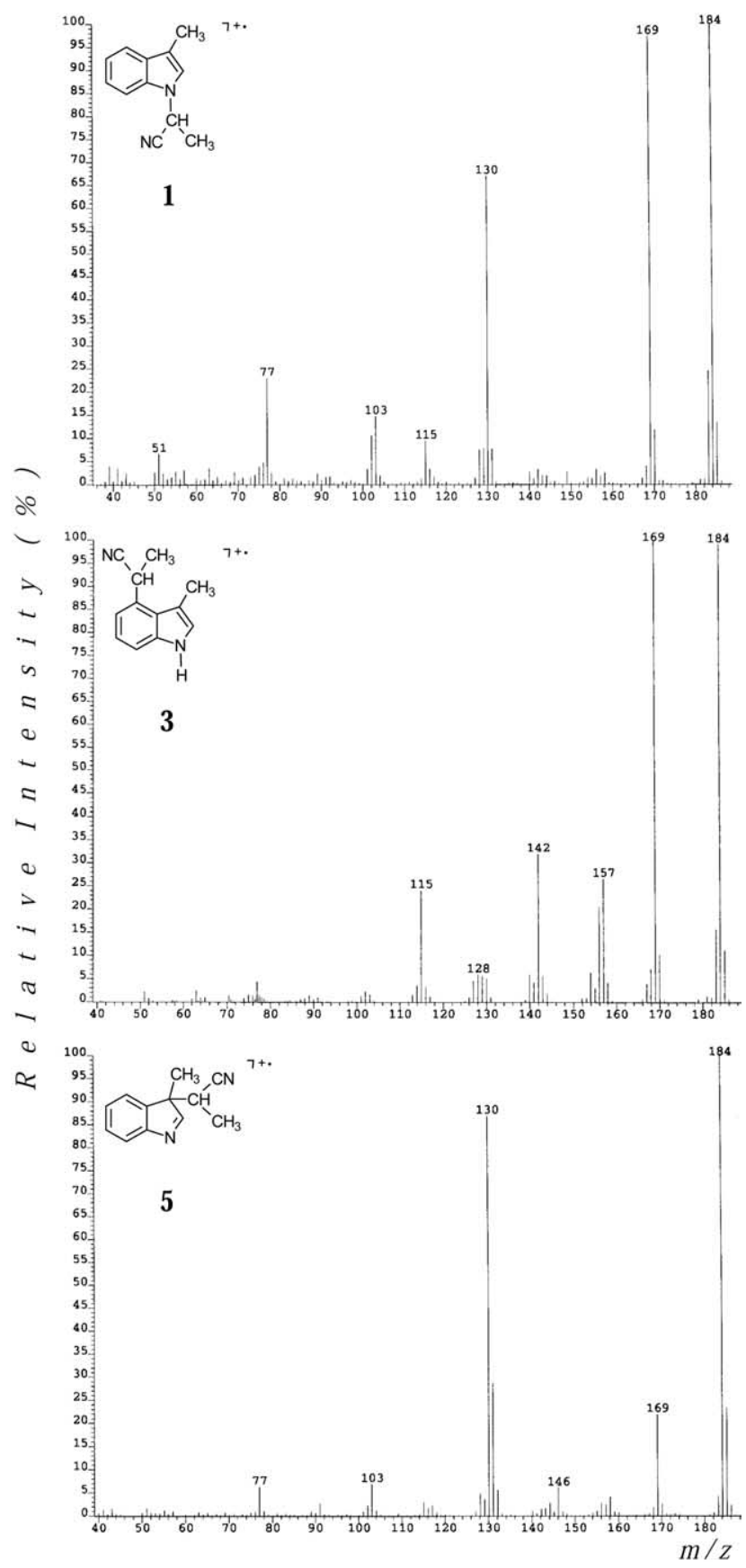

Figure 1. Comparison of the electron ionization $(70 \mathrm{eV})$ mass spectra of derivatives $\mathbf{1}$ (top), $\mathbf{3}$ (middle), and $\mathbf{5}$ (bottom). 
Table 1. Mass spectrometric data $(\mathrm{m} / \mathrm{z}$, relative intensity $(\%))$ for compounds 1-5

\begin{tabular}{lrrrrr}
\hline & \multicolumn{5}{c}{ Compound } \\
\cline { 2 - 6 }$m / z$ & $\mathbf{1}$ & $\mathbf{2}$ & $\mathbf{3}$ & $\mathbf{4}$ & $\mathbf{5}$ \\
\hline \hline 184 & 100 & 60.5 & 98.9 & 61.2 & 100 \\
183 & 25.0 & 9.4 & 15.5 & 14.6 & 4.9 \\
169 & 97.8 & 100 & 100 & 100 & 22.5 \\
168 & 4.2 & 11.9 & 8.5 & 18.3 & 1.3 \\
157 & 2.0 & 5.3 & 28.0 & 2.0 & 2.7 \\
156 & 3.7 & 8.1 & 21.7 & 3.9 & 2.7 \\
154 & 1.7 & & 6.3 & 2.7 & \\
146 & & 2.3 & 1.0 & & 6.7 \\
142 & 3.8 & 10.7 & 33.1 & 3.1 & 1.3 \\
140 & 2.2 & 5.9 & 6.1 & 6.4 & 1.0 \\
131 & 8.1 & & 1.0 & 9.2 & 29.0 \\
130 & 67.3 & 16.4 & 5.3 & 25.5 & 86.9 \\
129 & 7.9 & 4.5 & 5.7 & 4.9 & 3.6 \\
128 & 7.6 & 7.8 & 6.1 & 4.7 & 5.3 \\
115 & 9.7 & 9.7 & 25.0 & 5.4 & 2.9 \\
103 & 15.1 & 5.1 & 1.5 & 5.4 & 7.1 \\
102 & 10.1 & 4.3 & 2.3 & 4.4 & 2.3 \\
77 & 23.0 & 11.8 & 4.2 & 9.6 & 6.4 \\
\hline
\end{tabular}

hydrogen is observed for all the isomers but large differences in the relative abundances of the ions [M $1]^{+}$occur. The lowest relative intensity is observed for the $3 \mathrm{H}$-indole derivative 5 followed by Isomer 2 that has the $\alpha$-cyanoethyl substituent at position 2 of the indolic ring. This fragmentation also occurs for 3-methylindole and produces $[\mathrm{M}-1]^{+}$ions that are the most abundant ions in its mass spectrum. In that case the formation of a quinolinium ion has been proposed $[20,21]$. Similarly, a ring expansion of the five membered ring, yielding a stable substituted quinolinium ion at $m / z 183$, can be proposed for Compounds 1-4 (Scheme 2).

One of the most important fragmentation pathways followed by $\alpha$-cyanoethylindoles 1-4 involves the elimination of a methyl radical and produces intense ions at $m / z$ 169 ${ }^{\circ}$ Table $^{\circ} 1$, ${ }^{\circ}$ Figure $\left.^{\circ} 1\right){ }^{\circ}{ }^{\circ} s^{\circ} 3$-methylindole ${ }^{\circ}$ does ${ }^{\circ}$ not show the loss ${ }^{\circ}{ }^{\circ}$ a methyl'radical [4], it 'is reasonable that in the compounds under investigation the elimination of $\mathrm{CH}_{3}$ occurs from the $\alpha$-cyanoethyl moiety (see below). This fragmentation occurs also for 5 , even if ions $\left[\mathrm{M}-\mathrm{CH}_{3}\right]^{+}$have low relative intensity $(22.5 \%)$.

Loss of the methyl group followed/preceded by elimination of a hydrogen atom loss produces ions at $\mathrm{m} / \mathrm{z} 168$ that are abundant for 2 and 4 . This pathway is $\mathrm{a}^{\circ \text { "violation" }}{ }^{\circ} \mathrm{of}^{\circ}$ the $\mathrm{e}^{\circ}$ even-electron ${ }^{\circ}$ rule $^{\circ}[22]^{\circ}$ and ${ }^{\circ}$ it $^{\circ}$ yields a radical cation in which extensive delocalization is possible. Similar "violations" often occur when new fused rings are formed and it has been observed also in indole $^{\circ}$ derivatives ${ }^{\circ}[23]$.

Elimination of $\mathrm{HCN}$ from the molecular ions of Compounds 1-5 produces ions at $m / z$ 157. While for most of the isomers their intensity is quite low, ranging from $2.0(\mathbf{1}, \mathbf{4})$ to $5.3 \%(2)$, they are intense for $3(28.0 \%)$ (Figure 1 ). Isomer 3 also ${ }^{\circ}$ shows $^{\circ}$ quite intenseions ${ }^{\circ}$ at $\mathrm{m} / \mathrm{z}$ 156 due to $[(\mathrm{M}-\mathrm{H})-\mathrm{HCN}]^{+}\left(\left[\mathrm{C}_{11} \mathrm{H}_{10} \mathrm{~N}\right]^{+}\right.$theoretical: 156.0813, ${ }^{\circ}$ observed: ${ }^{\circ} 156.0809^{\circ}$ Th $)^{\circ}\left(\right.$ Figure $\left.^{\circ} 1\right)$.
Another relevant fragmentation process occurring in the ion source yields intense ions at $\mathrm{m} / \mathrm{z} 130$. These formally correspond to the loss of $54 \mathrm{u}$ from the molecular ions, and might be produced by loss of the $\alpha$-cyanoethyl radical, or by two consecutive losses of HCN. Accurate mass measurements have shown that the former pathway occurs. The relative intensities of these ions are high for Isomers 5 (86.9) and $\mathbf{1}(67.3 \%)$ and ${ }^{\circ}$ less $^{\circ}$ for $^{\circ}$ the $^{\circ}$ other ${ }^{\circ}$ isomers $^{\circ}\left(\right.$ Figure $^{\circ} 1,{ }^{\circ}$ Table $\left.^{\circ} 1\right) .{ }^{\circ}$ From ions at $m / z 130$, a loss of HCN should occur, thus yielding ions at $\mathrm{m} / \mathrm{z} 103$ (see below). Differently from the indole Isomers $\mathbf{1 - 4}$, the $3 \mathrm{H}$-indole derivative $\mathbf{5}$ produces intense ions at $m / z 131$ due to the loss of $\mathrm{C}_{3} \mathrm{H}_{3} \mathrm{~N}$ from the $\alpha$-cyanoethyl group.

Regarding ions with lower $m / z$ ratios, note the presence of the species at $\mathrm{m} / \mathrm{z} 115$ that are abundant for Isomer $3(25.0 \%)$. Two fragmentation pathways might contribute to their formation: one might involve the consecutive losses of the $\alpha$-cyanoethyl substituent and $\mathrm{CH}_{3}$, yielding the radical cation $\left[\mathrm{C}_{8} \mathrm{H}_{5} \mathrm{~N}\right]^{+\cdot}$ (theoretical mass 115.0422). The other might consist in the elimination of $\mathrm{CH}_{3}$ and two molecules of $\mathrm{HCN}$, thus producing ions $\left[\mathrm{C}_{9} \mathrm{H}_{7}\right]^{+}$whose theoretical mass is 115.0548 . Accurate mass measurements carried out at resolution 10,000 $\mathrm{M} / \Delta \mathrm{M}$, that is enough to separate the two hypothesized ionic species, have allowed to determine that the composition of ions at $m / z 115$ corresponds to $\left[\mathrm{C}_{9} \mathrm{H}_{7}\right]^{+}$for all the isomers. It follows that a methyl radical from the $\alpha$-cyanoethyl substituent, and two HCN molecules, one from the substituent and the other from the indole ring, are involved in this pathway.

\section{Deuterium Labeled Derivatives and Theoretical Calculations}

Aimed at going deeply into the gas phase behavior of this class of isomers, especially for evaluating which methyl group is more easily eliminated, i.e., that bound to the heteroaromatic system or that belonging to the pendant side chain, deuterium labeled derivatives $1 d_{1}-5 d_{1}, 3 d_{2}$, $1 d_{3}-5 d_{3}$ (Scheme 1) have been synthesized. All derivatives $1 d_{3}-5 d_{3}$ show the specific and selective losses of 1 and $17 \mathrm{u}$ from their molecular ions. This indicates that one hydrogen atom not belonging to the pendant side chain and the $\mathrm{CHD}_{2}$ radical of the $\alpha$-cyanoethyl moiety are selectively lost. It follows that the loss of $15 \mathrm{u}$ observed in nondeuterated compounds involves the methyl group of the<smiles>[R]c1cc([R3])c2c(C)c([R2])n([R1])c2c1</smiles>

$1-4, m / z 184$

$m / z 183$

Scheme 2 


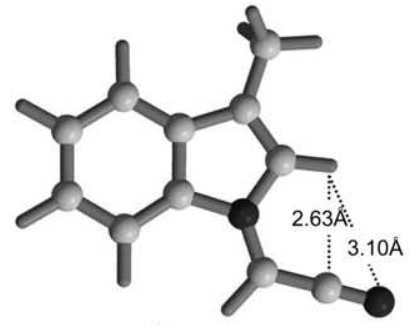

1a

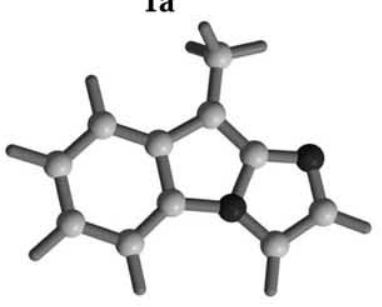

$1 \mathrm{c}$

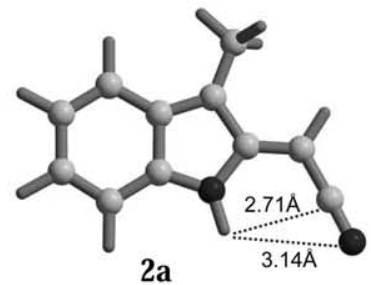

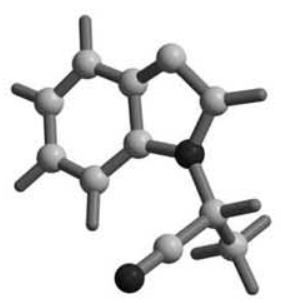

$1 \mathrm{~b}$

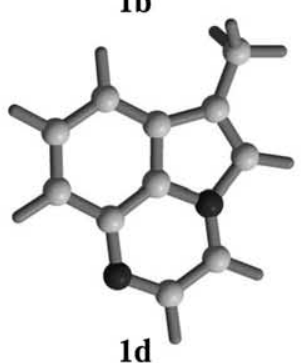

1d

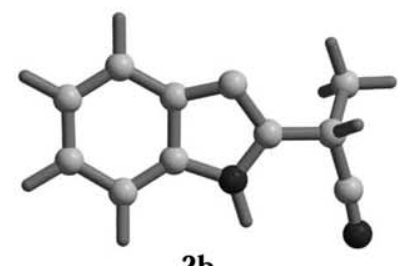

2b

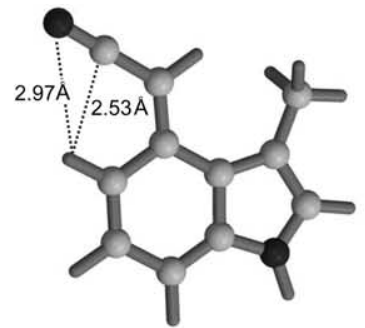

3a
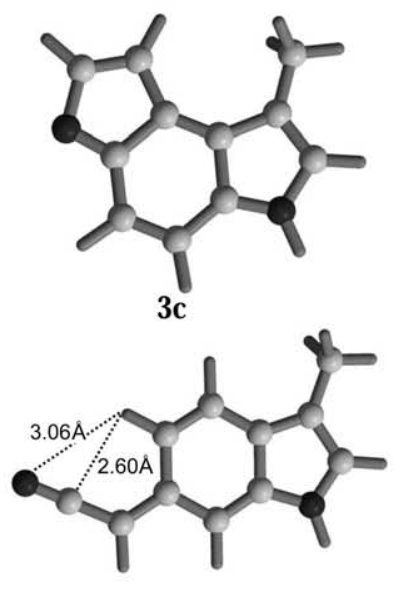

4a
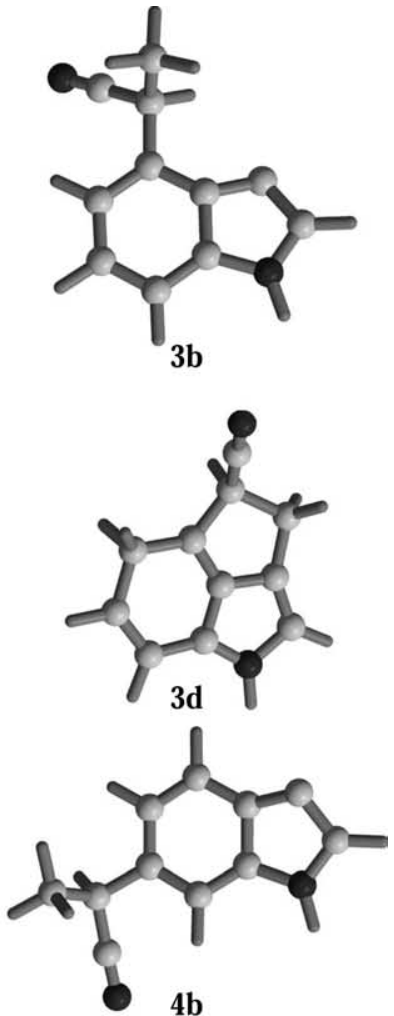

Figure 2. Energy minimized structures proposed for the $\left[\mathrm{M}-\mathrm{CH}_{3}\right]^{+}$cations formed by Isomers 1-4.

$\alpha$-cyanoethyl substituent. It also strongly suggests that the $[\mathrm{M}-1]^{+}$ions are due to elimination of a hydrogen atom from the methyl group at position 3 of the indole, in agreement ${ }^{\circ}$ with $^{\circ}$ previous $^{\circ}$ data $^{\circ}[20,21]$.

Deuterium labeled compounds have been also very useful to elucidate the consecutive eliminations of two $\mathrm{HCN}$ molecules from the ions $\left[\mathrm{M}-\mathrm{CH}_{3}\right]^{+}$observed in the mass spectra of Isomers 1-5. In fact, the mass spectra of $1 d_{3}-5 d_{3}$ show the formation of ions at $m / z 143$ and 116 attributable to $\left[\left(\mathrm{M}-\mathrm{CHD}_{2}\right)-\mathrm{HCN}\right]^{+}$and $[(\mathrm{M}$ $\left.-\mathrm{CHD}_{2}\right)-2 \mathrm{HCN}^{+}$, respectively. It follows that one deuterium atom is still present in the ions at $m / z 116$. The study of the decompositions of $3 d_{2}$ has shown the formation of ions at $m / z 143$ and 115, due to [(M $\left.\mathrm{CH}_{2} \mathrm{D}\right)-\mathrm{HCN}^{+}$and $\left[\left(\left\{\mathrm{M}-\mathrm{CH}_{2} \mathrm{D}\right\}-\mathrm{HCN}\right)-\right.$ $\mathrm{DCN}^{+}$, respectively. It suggests that, after elimination of the methyl radical, the elimination of $\mathrm{HCN}$ involves the cyano group of the pendant side chain and one hydrogen atom of the 3-methyl group or of the heterocyclic system. After the first loss of $\mathrm{HCN}$, the following one involves the indole ring with the selective elimination of the hydrogen bound to the nitrogen atom.

Table 2. Calculated energies of different structures for $\left[\mathrm{M}-\mathrm{CH}_{3}\right]^{+}$ions $(\mathrm{m} / \mathrm{z} 169)$ proposed from Isomers 1-4

\begin{tabular}{|c|c|c|c|c|}
\hline Species & B3LYP $6-31 G(d, p)^{a}$ & $\mathrm{ZPVE}^{\mathrm{b}}$ & $\mathrm{SCF}+\mathrm{ZPVE}^{\mathrm{a}}$ & $\begin{array}{c}\Delta \mathrm{E} \\
(\mathrm{SCF}+\mathrm{ZPVE})^{\mathrm{c}}\end{array}$ \\
\hline$[1 \mathrm{a}]^{+}$ & -533.814043 & 0.154281 & -533.659762 & 0 \\
\hline$[1 b]^{+}$ & -533.692079 & 0.153027 & -533.539052 & 75.75 \\
\hline$[1 \mathrm{c}]^{+}$ & -533.843388 & 0.155996 & -533.687392 & -17.34 \\
\hline$[1 d]^{+}$ & -533.863432 & 0.157368 & -533.706064 & -29.05 \\
\hline$[2 \mathrm{a}]^{+}$ & -533.837327 & 0.154511 & -533.682816 & 0 \\
\hline$[2 b]^{+}$ & -533.710318 & 0.153112 & -533.557206 & 78.82 \\
\hline$[3 \mathbf{a}]^{+}$ & -533.829920 & 0.155228 & -533.674692 & 0 \\
\hline$[3 b]^{+}$ & -533.704099 & 0.153200 & -533.550899 & 77.68 \\
\hline$[3 c]^{+}$ & -533.808197 & 0.155807 & -533.652390 & 13.99 \\
\hline$[3 d]^{+}$ & -533.803041 & 0.156213 & -533.646828 & 17.48 \\
\hline$[4 a]^{+}$ & -533.832674 & 0.154813 & -533.677861 & 0 \\
\hline$[4 b]^{+}$ & -533.703058 & 0.153187 & -533.549871 & 80.31 \\
\hline
\end{tabular}

${ }^{a}$ units of Hartree.

bZero point vibrational energies corrected by 0.893 ; units of Hartree/particle.

${ }^{\mathrm{c}} \mathrm{kcal} \mathrm{mol}$. $^{-1}$ 


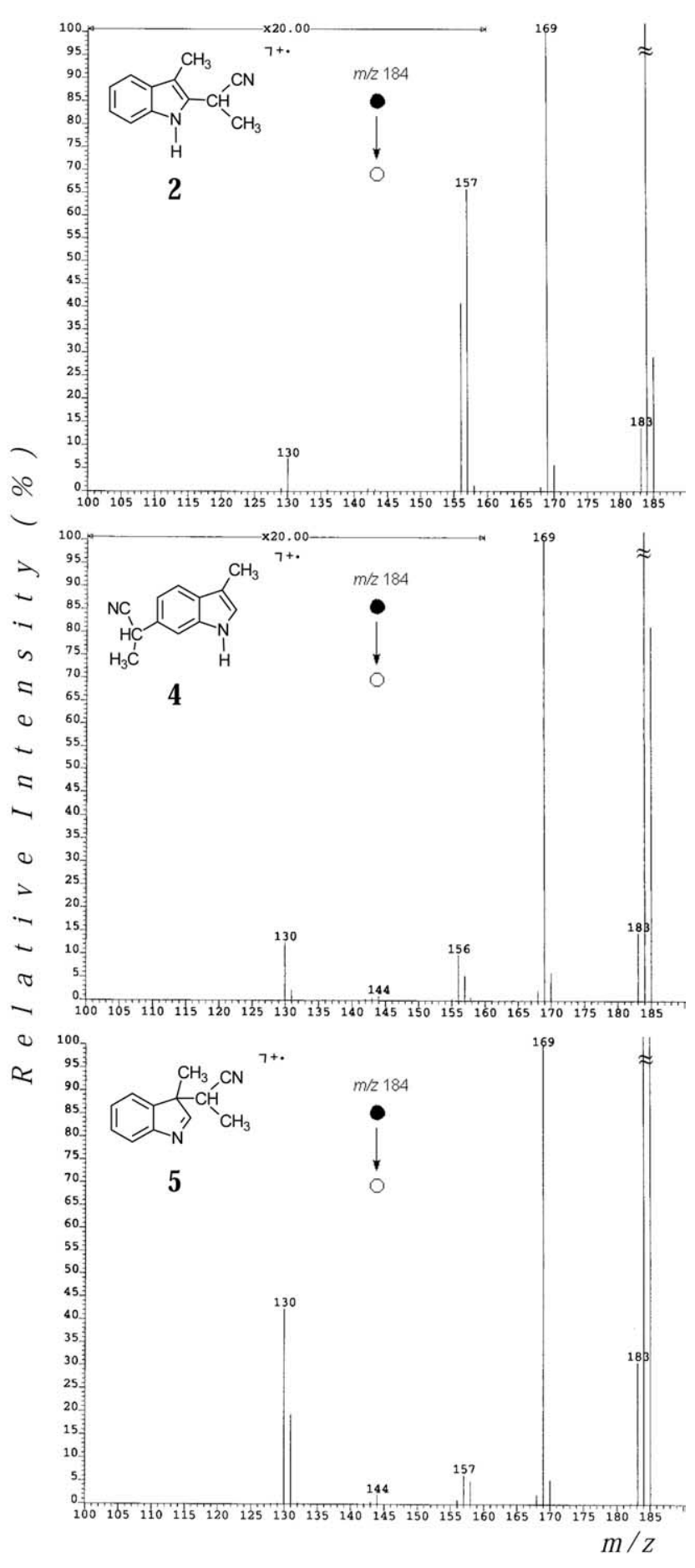

Figure 3. Metastable product ion spectra of molecular ions $(\mathrm{m} / \mathrm{z}$ 184) of Isomers 2 (top), 4 (middle), and 5 (bottom).

Theoretical calculations have been carried out to evaluate the stability of different $\left[\mathrm{M}-\mathrm{CH}_{3}\right]^{+}$structures produced by Compounds 1-4. Concerning Isomer 1 , the B3LYP 6-31G $(\mathrm{d}, \mathrm{p})$ data have shown that the elimination of the methyl group from the pendant substituent $(\mathbf{1 a}$, Figure $\left.^{\circ} 2\right)^{\circ}$ is $^{\circ}$ much $^{\circ}$ more $^{\circ}$ favored ${ }^{\circ}$ than ${ }^{\circ}$ that $^{\circ}$ from ${ }^{\circ}$ the position $3^{\circ}$ of $^{\circ}$ the ${ }^{\circ}$ pyrrole ${ }^{\circ}$ ring $^{\circ}\left(\mathbf{1 b},{ }^{\circ}\right.$ Figure 2$)$. ${ }^{\circ}$ The ${ }^{\circ}$ energy difference of the two structures is quite high $(\Delta \mathrm{E}$
Table 3. Metastable product ion MS/MS data $(\mathrm{m} / \mathrm{z}$, relative intensity $(\%))$ for molecular ions $(m / z$ 184) of Compounds 1-5

\begin{tabular}{cccccc}
\hline & \multicolumn{5}{c}{ Compound } \\
\cline { 2 - 6 } $\begin{array}{c}\text { Product lon } \\
(\mathrm{m} / \mathrm{z})\end{array}$ & $\mathbf{1}$ & $\mathbf{2}$ & $\mathbf{3}$ & $\mathbf{4}$ & $\mathbf{5}$ \\
\hline \hline 183 & 58.4 & 14.0 & 28.0 & 15.0 & 31.2 \\
169 & 100 & 100 & 100 & 100 & 100 \\
167 & & & 3.2 & & \\
158 & & 1.0 & 1.2 & $<1$ & 5.0 \\
157 & & 3.3 & 31.7 & $<1$ & 6.5 \\
131 & 1.4 & & & & 19.6 \\
130 & 15.6 & $<1$ & & $<1$ & 42.6 \\
\hline
\end{tabular}

$(\mathbf{1 b}-\mathbf{1 a})^{\circ}={ }^{\circ} 75.75^{\circ} \mathrm{kcal}^{\circ} \mathrm{mol}^{-1},{ }^{\circ}$ Table 2$),{ }^{\circ}$ in ${ }^{\circ}$ full ${ }^{\circ}$ agreement with the experimental data. The same trend is followed by ions $\left[\mathrm{M}-\mathrm{CH}_{3}\right]^{+}$produced by 2-4 (Figure2, Table2) with energy differences between the two structures $[\Delta \mathrm{E}$ (b-a)] ranging from 77.68 (3) to $80.31 \mathrm{kcal} \mathrm{mol}^{-1}$ (4).

In structures 1a-4a hydrogen bonding interactions occur between the nitrogen of the cyano group and a hydrogen atom of the heterocyclic system with $-\mathrm{C} \equiv \mathrm{N}$ ... H distances in the range $2.97 \AA(\mathbf{3 a}) \div 3.14 \AA \mathbf{( 2 a})$ (Figure 2 ). ${ }^{\circ}$ This ${ }^{\circ}$ proximity ${ }^{\circ}$ effect ${ }^{\circ}$ should ${ }^{\circ}$ allow ${ }^{\circ}{ }^{\circ}$ nucleophylic attack of the nitrogen of the cyano group to an aromatic carbon followed by hydrogen rearrangement, thus yielding the formation of fused tricyclic structures. Some of them, i.e., $\mathbf{1 c}, \mathbf{1 d}, \mathbf{3 c}, \mathbf{3 d}$, possibly produced by elimination of the methyl group from Isomers $\mathbf{1}$ and $\mathbf{3}$, have been submitted to energy minimization. Regarding the ions $\left[\mathrm{M}-\mathrm{CH}_{3}\right]^{+}$formed from Isomer 1, both tricyclic ${ }^{2}$ tructures $1 \mathrm{c}$ and $1 \mathbf{d}$ (Figure 2 ) result to be more stable than 1a, and 1d, formed by a $[6,6,5]$ fused ring system, ${ }^{\circ}$ is $^{\circ}$ the ${ }^{\circ}$ most $^{\circ}$ stable $^{\circ}\left(\right.$ Table $\left.^{\circ} 2\right){ }^{\circ}{ }^{\circ}$ In $^{\circ}$ contrast, ${ }^{\circ}$ both tricyclic structures proposed for the ions $\left[\mathrm{M}-\mathrm{CH}_{3}\right]^{+}$ obtained ${ }^{\circ}$ from $^{\circ}$ Isomer ${ }^{\circ} 3{ }^{\circ}$ i.e., ${ }^{\circ} \mathbf{3 c}$ and $^{\circ} \mathbf{3 d}$ (Figure 2 ), ${ }^{\circ}$ have an $^{\circ}$ energy $^{\circ}$ content $^{\circ}$ higher $^{\circ}$ than $^{\circ} 3 \mathbf{a}\left(\right.$ Table $\left.^{\circ} 2\right)$.

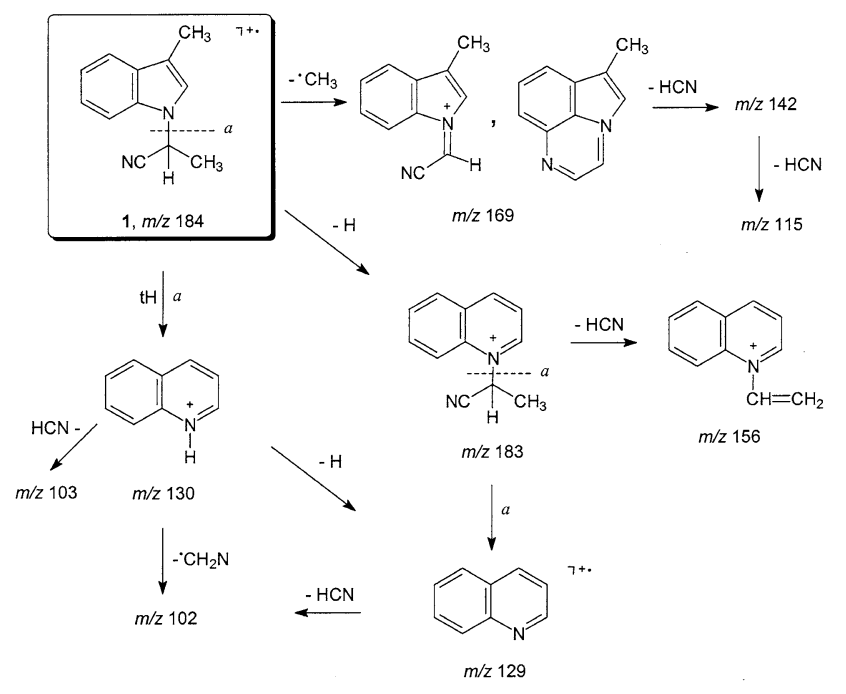

Scheme 3 

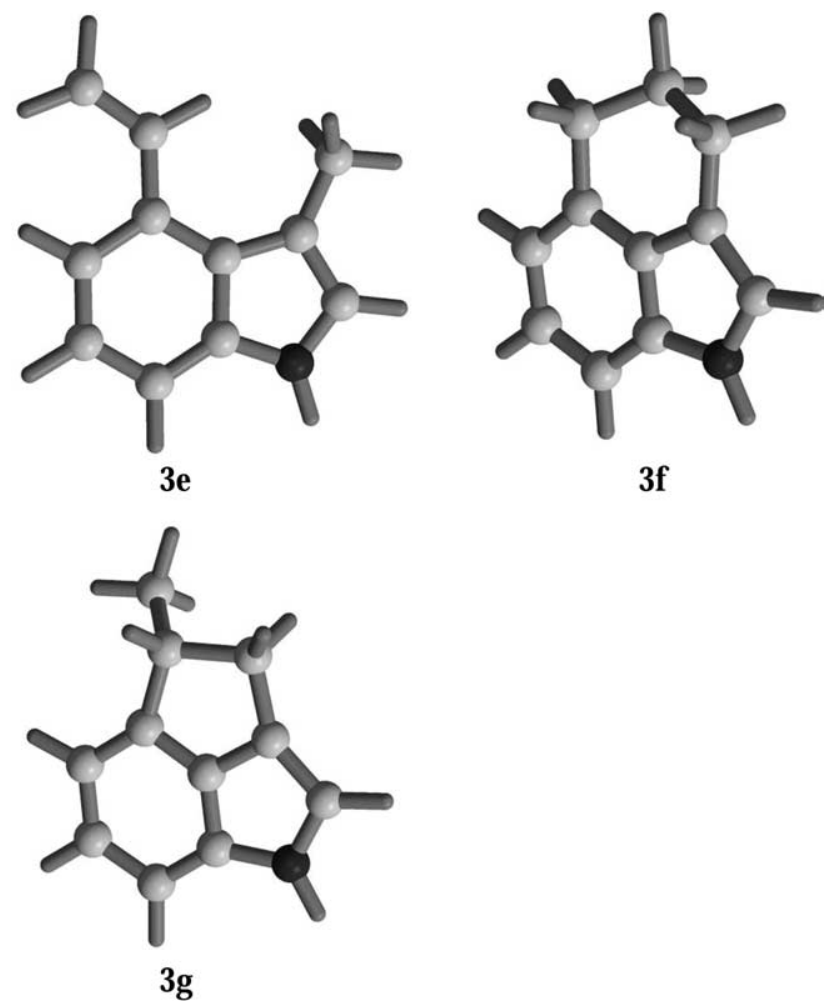

Figure 4. Energy minimized structures proposed for the $[\mathrm{M}-$ $\mathrm{HCN}^{+\cdot}$ radical cation $(m / z$ 157) formed by Isomer 3.

\section{Metastable Ion Decompositions}

Molecular ions. Metastable product ion mass spectra obtained by selecting the molecular ions show that Isomers 1-5 generally follow common decomposition pathways $^{\circ}\left(\right.$ Figure $^{\circ} 3,^{\circ}$ Table $\left.^{\circ} 3\right) .^{\circ}$ Large $^{\circ}$ differences $^{\circ}$ in relative abundances of product ions evidence that gas phase regiospecific reactions, depending upon the position of the $\alpha$-cyanoethyl moiety at the indolic ring, occur in the first field-free region of a double sector instrument.

In the metastable ion mass spectra of Isomers 1-5 the most abundant ions $(m / z 169)$ correspond to the elimination of a methyl radical that occurs from the $\alpha$-cyanoethyl moiety (see above).

The loss of hydrogen and that of a methyl radical represent the most significant metastable decompositions of the molecular ions of 2 and 4 . For this latter, consecutive losses $\mathrm{H}$ and $\mathrm{CH}_{3}$ from the molecular ion yield cations at $m / z 168$, whose relative intensity is higher than those observed for the other compounds.

Other distinctive and regiospecific pathways are detected as metastable ion processes. Distinctively for Isomers 1 and 5, the metastable loss of the $\alpha$-cyanoethyl substituent from $\mathrm{N}(1)$ (in 1) or from the hindered position 3 in $\mathbf{5}$, followed by rearrangement of one hydrogen atom can occur. This is in agreement with the behavior of monomethylindoles: among the seven possible isomers, only 1-methylindole shows the elimination $^{\circ}$ of ${ }^{\circ}$ the ${ }^{\circ}$ methy ${ }^{\circ}$ radical $^{\circ}[4] .^{\circ}{ }^{\circ}{ }^{\circ}$ the $^{\circ}$ case $^{\circ}$ of ${ }^{\circ}$ Isomers $^{\circ} 1$ and 5 , the loss of the $\alpha$-cyanoethyl substituent produces intense ions at $m / z 130$ with a possible quinolinium structure (Scheme 3).

Isomer 3, in which the substituent is at position 4 of the indolic ring, yields abundant metastable product ions at $m / z 157$ due to the elimination of HCN. In this compound, owing to the spatial proximity between the methyl and the $\alpha$-cyanoethyl substituents at the positions 3 and 4 of the indolic ring, respectively, fused tricyclic structures might be distinctively produced by 3. This is in agreement with the behavior of $3 d_{3}$ that specifically eliminates HCN. To evaluate the proximity effect in 3, theoretical calculations on three possible structures proposed for the radical cations at $m / z 157$ have been carried out. The calculations have shown that the structure $3 \mathbf{f}$, formed by a tricyclic fused $[6,6,5]$ ring system $^{\circ}\left(\right.$ Figure $\left.^{\circ} 4\right),{ }^{\circ}$ is $^{\circ}$ the $^{\circ}$ most $^{\circ}$ stable $^{\circ}\left(\right.$ Table $\left.^{\circ} 4\right) .^{\circ}$ Its formation involves a hydrogen rearrangement from the methyl group followed by cyclization. The decomposition pathway proposed for 3 is reported in Scheme 4.

$\left[\mathrm{M}-\mathrm{CH}_{3}\right]^{+}$fragment ions. The study of metastable ion mass spectra produced by fragment ions allows a better insight into the structural characterization and isomeric differentiation of Compounds 1-5. Furthermore it is useful to establish whether isomerization phenomena occur after partial decomposition of the molecular ion. It has been already shown that the methyl group is eliminated by the $\alpha$-cyanoethyl substituent from Compounds 1-5 (see above).

As a general remark, by analyzing the metastable product ion mass spectra obtained by selecting the species $\left[\mathrm{M}-\mathrm{CH}_{3}\right]^{+}(\mathrm{m} / \mathrm{z} 169)$, it results that structural Isomers $\mathbf{1}$ and $\mathbf{5}$ show quite extensive decomposition pathways in comparison with the other analogs 2-4 (Figure ${ }^{\circ},{ }^{\circ}$ Table ${ }^{\circ}$ ).

Table 4. Calculated energies of different structures for $[\mathrm{M}-\mathrm{HCN}]^{+} \cdot$ ions $(\mathrm{m} / \mathrm{z}$ 157) proposed from Isomer 3

\begin{tabular}{|c|c|c|c|c|c|}
\hline Species & B3LYP 6-31G $(d, p)^{a}$ & $\mathrm{ZPVE}^{\mathrm{b}}$ & $\mathrm{SCF}+\mathrm{ZPVE}^{\mathrm{a}}$ & $\begin{array}{c}\Delta \mathrm{E} \\
(\mathrm{SCF}+\mathrm{ZPVE})^{\mathrm{c}}\end{array}$ & $S^{2}$ \\
\hline $3 e$ & -480.302943 & 0.170554 & -480.132389 & 11.11 & 0.767 \\
\hline $3 f$ & -480.324048 & 0.173956 & -480.150092 & 0 & 0.759 \\
\hline $3 g$ & -480.290865 & 0.172571 & -480.118294 & 19.95 & 0.758 \\
\hline
\end{tabular}

aunits of Hartree.

bero point vibrational energies corrected by 0.893 ; units of Hartree/particle.

${ }^{\mathrm{c}} \mathrm{kcal}$ mol. ${ }^{-1}$ 


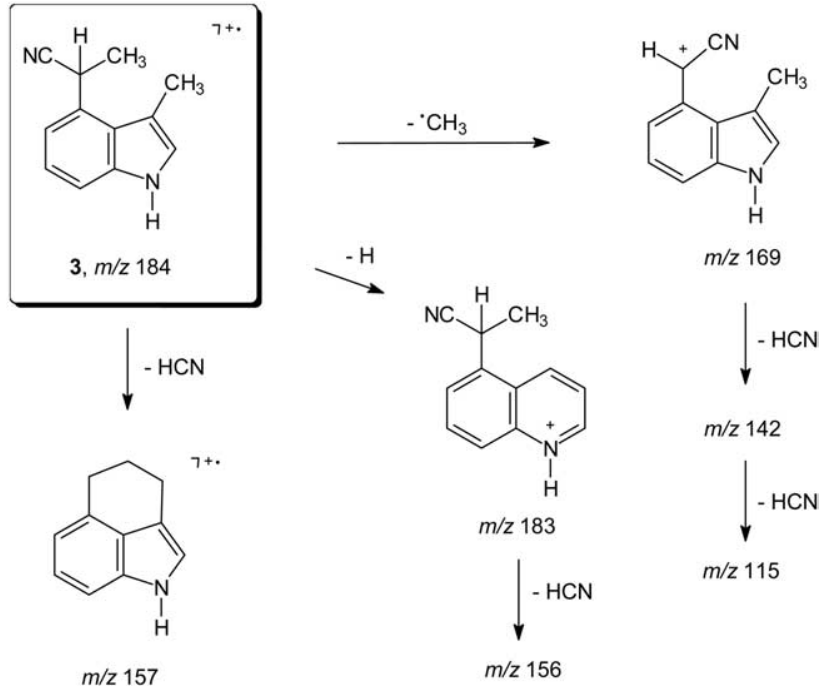

Scheme 4

Two main common decomposition pathways can be envisaged for all the compounds. One involves the loss of hydrogen and the other the loss of HCN. Also in this case important regiospecific effects are evidenced by large differences in the relative abundances of product

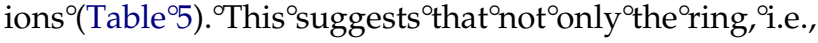
benzene or pyrrole, to which the pendant substituent is bound, but also the substitution at different positions in a given ring plays an important role in the regiochemical effects and isomeric differentiation. The elimination of a hydrogen atom produces very abundant ions at $\mathrm{m} / \mathrm{z}$ 168 for 1, 4 and 5. On the other hand, ions at $\mathrm{m} / \mathrm{z} 142$, due to $\left[\left(\mathrm{M}-\mathrm{CH}_{3}\right)-\mathrm{HCN}\right]^{+}$, are the most abundant ions in the case of Isomers $\mathbf{2}$ and $\mathbf{3 .}$

Compounds 1 and 2, both having the substituent on the pyrrole ring, can be easily differentiated. For $\mathbf{1}$, the $\left[\left(\mathrm{M}-\mathrm{CH}_{3}\right)-\mathrm{H}\right]^{+\cdot}$ ions are the most abundant, while the $\left[\left(\mathrm{M}-\mathrm{CH}_{3}\right)-\mathrm{HCN}\right]^{+}$ions $(\mathrm{m} / z$ 142) have relative intensity equal to $69.4 \%$. On the other hand, the opposite $^{\circ}$ trend $^{\circ}$ is $^{\circ}$ observed $^{\circ}$ for $^{\circ} 2$ (Figure ${ }^{\circ} 5$ )..$^{\circ}$ In $^{\circ}$ addition, Isomer ${ }^{\circ} 1$ shows $^{\circ}$ an $^{\circ}$ intense ${ }^{\circ}$ peak $^{\circ}$ at $^{\circ} \mathrm{m} / \mathrm{z} 115^{\circ}$ (Figure $^{\circ}$ ). This can be attributable to two consecutive losses of $\mathrm{HCN}$ from the $\left[\mathrm{M}-\mathrm{CH}_{3}\right]^{+}$ions whose overall rate is higher than the flight time of the ions in the first field-free region, thus allowing to detect only the final product ions.

Similarly, Isomers 3 and $\mathbf{4}$, in which the substituent is at two different positions of the benzene ring, show an analogous competition between the losses of $\mathrm{H}$ and $\mathrm{HCN}$, the latter being much more abundant for Isomer 3.

The metastable product ion mass spectrum of the [M $\left.-\mathrm{CH}_{3}\right]^{+}$ions formed by the pyrrolidine 5 partly resembles that produced by 1 . A remarkable differentiation is the presence of intense ions at $m / z 115$ for 1 and $128^{\circ}$ for $^{\circ} 5$ (Figure $^{\circ}{ }^{\circ},{ }^{\circ}$ Table $^{\circ}$ ).$^{\circ}{ }^{\circ}$ The $^{\circ}$ latter $^{\circ}$ species $^{\circ}$ are attributable to the elimination of $\mathrm{C}_{2} \mathrm{H}_{3} \mathrm{~N}$ from the species $\left[\mathrm{M}-\mathrm{CH}_{3}\right]^{+}$produced by 5 . The decomposition pathway proposed for $\mathbf{5}$ is shown in Scheme $\mathbf{5}$.

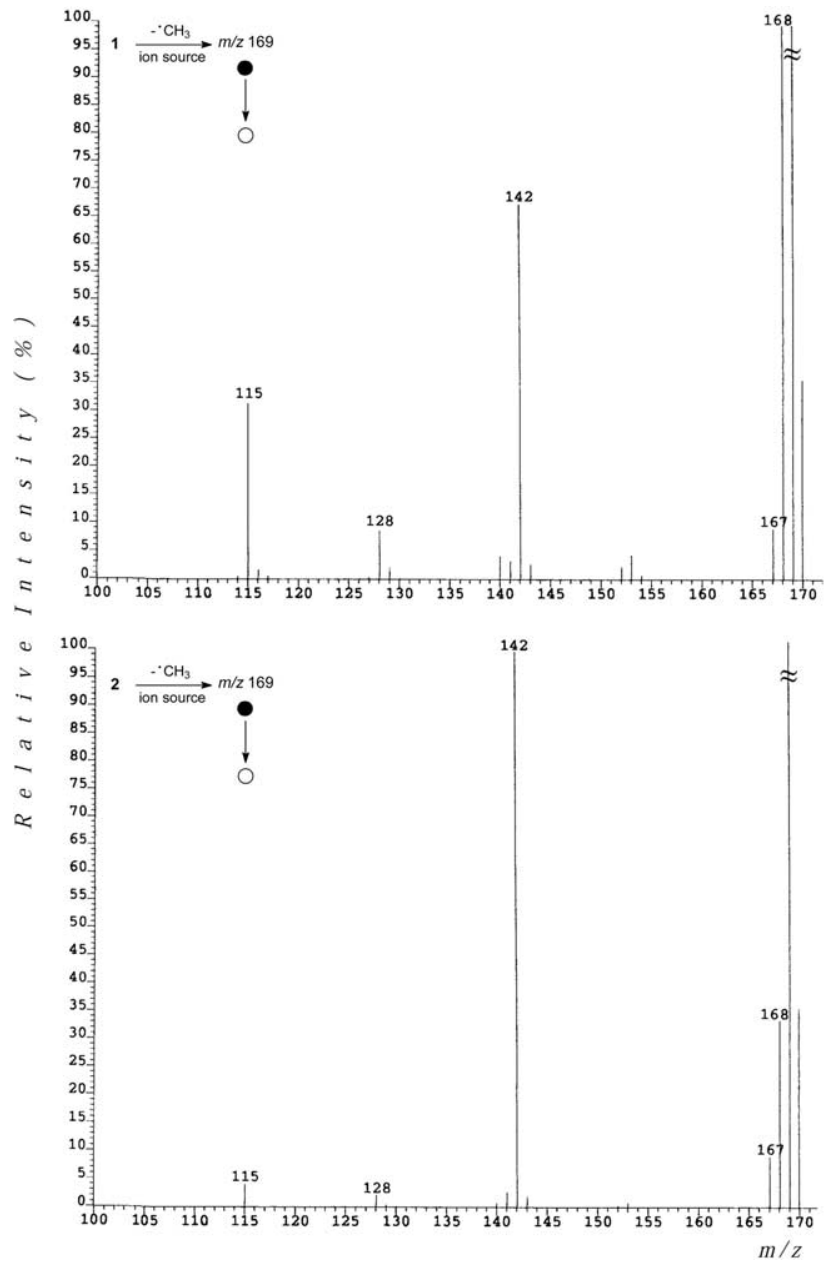

Figure 5. MS/MS product ion spectra obtained by selecting the $\left[\mathrm{M}-\mathrm{CH}_{3}\right]^{+}$fragment ions ( $m / z$ 169) from Isomers $\mathbf{1}$ (top) and 2 (bottom).

$\left[\mathrm{M}-\mathrm{CH}(\mathrm{CN}) \mathrm{CH}_{3}\right]^{+}$fragment ions. Owing to the elimination of the $\mathrm{CH}(\mathrm{CN}) \mathrm{CH}_{3}$ radical from the molecular ions of Compounds 1-5, cations with elemental composition $\left[\mathrm{C}_{9} \mathrm{H}_{8} \mathrm{~N}\right]^{+}(\mathrm{m} / \mathrm{z} 130)$ are produced. These differ from each other for the formal location of the positive charge. In adition, they are isobaric with the $[\mathrm{M}-\mathrm{H}]^{+}$ ions obtained from 3-methylindole.

Table 5. Metastable MS/MS data $(\mathrm{m} / \mathrm{z}$, relative intensity $(\%))$ for $\left[\mathrm{M}-\mathrm{CH}_{3}\right]^{+}$ions $(m / z$ 169) produced from Compounds 1-5

\begin{tabular}{cccccr}
\hline & \multicolumn{5}{c}{ Compound } \\
\cline { 2 - 6 } $\begin{array}{c}\text { Product lon } \\
(\mathrm{m} / \mathrm{z})\end{array}$ & $\mathbf{1}$ & $\mathbf{2}$ & $\mathbf{3}$ & $\mathbf{4}$ & $\mathbf{5}$ \\
\hline \hline 168 & 100 & 35.5 & 5.6 & 100 & 100 \\
167 & 7.9 & & & & 3.8 \\
153 & 7.8 & & & & 5.7 \\
143 & 2.4 & 1.7 & 3.8 & & 1.9 \\
142 & 69.4 & 100 & 100 & 12.4 & 71.1 \\
141 & 3.6 & 2.9 & & 2.9 & 3.7 \\
140 & 4.6 & $<1$ & & & \\
128 & 8.3 & 1.9 & & & 21.4 \\
115 & 33.6 & 4.0 & & & 8.2 \\
\hline
\end{tabular}


Metastable ion spectra of ions at $m / z 130$ produced by ${ }^{\circ}$ Isomers ${ }^{\circ}$-5 are $^{\circ}$ quite $^{\circ}$ similar $^{\circ}$ each $^{\circ}$ other $^{\circ}\left(\right.$ Table $\left.^{\circ} 6\right)$. Most of the decompositions involve the dismantling of the five membered ring, and mainly consist in the elimination of HCN. This produces ions at $m / z 103$ that are the most intense ions for all the isomers (Table $\left.{ }^{\circ} 6\right)$.

It has been found that the elimination of HCN from the indole proceeds through several mechanisms, involving hydrogen scrambling and rearrangement of carbon ${ }^{\circ}$ atoms $[6,7]$. Similarly, it is ${ }^{\circ}$ reasonable that ${ }^{\circ}$ these reactions might occur in some extent also in the species under investigation, producing closely related metastable ion spectra. In particular, the high similarity between the metastable spectra of the ions $\left[\mathrm{C}_{9} \mathrm{H}_{8} \mathrm{~N}\right]^{+}$ produced by $\mathbf{1}$ and $\mathbf{5}$ suggests that, owing to hydrogen rearrangement, these ions might have a common quinolinium structure.

Other metastable ion decompositions involve the loss of one and two hydrogen atoms. The latter reaction produces $\left[\mathrm{C}_{9} \mathrm{H}_{6} \mathrm{~N}\right]^{+}$ions $(\mathrm{m} / z$ 128) whose relative intensities are generally high $(22 \div 43 \%$, Table $\left.^{\circ} 6\right) .^{\circ}$ The $^{\circ} \operatorname{loss}^{\circ}$ of $^{\circ}$ the $^{\circ}$ methy $^{\circ}$ group $^{\circ}$ is $^{\circ}$ observed from Isomers 2 and 3.

\section{Conclusions}

Different mass spectrometry and MS/MS techniques have shown to be useful tools for the structural characterization and differentiation of indolic isomers obtained by photochemical reactions. These compounds can play a role in different synthetic pathways.

The study of the mass spectra of Isomers 1-5 and of their deuterium labeled derivatives has allowed to evidence differences in relative intensities of ions produced in the ion source depending on the position of the substituent at the indolic ring. Metastable ion MS/MS experiments have allowed to evidence specificity and selectivity of gas phase unimolecular reactions. The product ion spectra obtained by selecting the molecular ions from Isomers 1-5 have shown distinctive and specific reaction pathways for each compound.

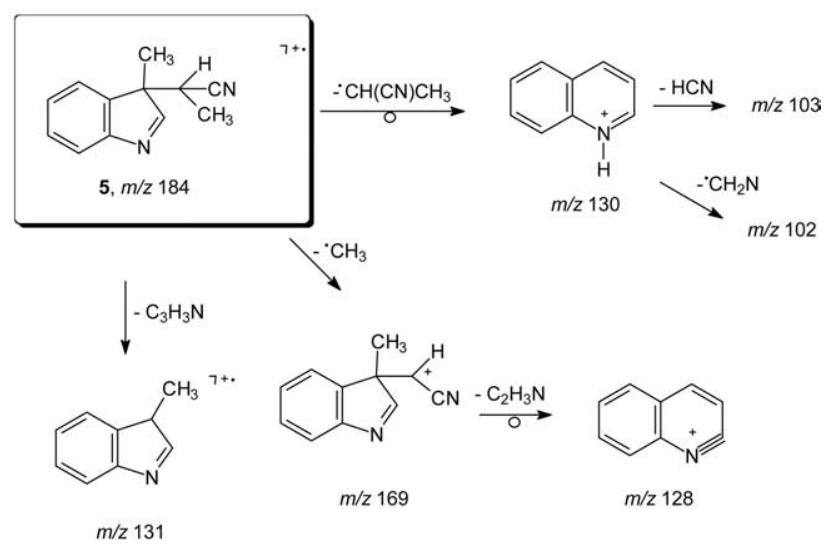

Scheme 5
Table 6. Metastable MS/MS data $(\mathrm{m} / \mathrm{z}$, relative intensity $(\%))$ for $\left[\mathrm{M}-\mathrm{CH}(\mathrm{CN}) \mathrm{CH}_{3}\right]^{+}$ions $(\mathrm{m} / \mathrm{z}$ 130) produced from Compounds 1-5

\begin{tabular}{cccccc}
\hline & \multicolumn{5}{c}{ Compound } \\
\cline { 2 - 6 } $\begin{array}{c}\text { Product lon } \\
(\mathrm{m} / \mathrm{z})\end{array}$ & $\mathbf{1}$ & $\mathbf{2}$ & $\mathbf{3}$ & $\mathbf{4}$ & $\mathbf{5}$ \\
\hline \hline 129 & 10.0 & 21.0 & 43.3 & 7.9 & 17.1 \\
128 & 37.6 & 35.5 & 35.3 & 22.1 & 42.6 \\
115 & & 3.0 & 11.7 & & \\
103 & 100 & 100 & 100 & 100 & 100 \\
102 & 4.3 & & 7.8 & & 3.0 \\
\hline
\end{tabular}

When the $\alpha$-cyanoethyl substituent is bound to the indolic nitrogen, the elimination of such a substituent is a distinctive and regiospecific reaction that occurs in the gas phase. It is produced both in the ion source by high internal energy ions and under the metastable energy frame.

The investigation has also been extended to the study of metastable decompositions produced by most intense fragment ions formed in the source. After the loss of a methyl radical, distinctive and specific metastable ion spectra are produced by each compound, thus suggesting that isomerization processes do not occur. High level theoretical calculations have been used to evaluate the stability and chemico-physical properties of different ion structures proposed for the ions $\left[\mathrm{M}-\mathrm{CH}_{3}\right]^{+}$.

Owing to the elimination of the radical $\mathrm{CH}(\mathrm{CN}) \mathrm{CH}_{3}$ from the molecular ions, very similar metastable ion spectra are produced. This similarity suggests that scrambling and/or rearrangement reactions might occur at some extent in the decomposition of the ionic species at $m / z 130$.

This study has allowed to characterize and differentiate each $\alpha$-cyanoethylindole isomer and to evaluate the role exerted by the nature and position of the substituent on the gas phase processes.

\section{References}

1. Beljanski, M.; Beljanski, M. S. Three Alkaloids as Selective Destroyers of Cancer Cells in Mice. Synergy with Classic Anticancer Drugs. Oncology 1986, 43, 198-203.

2. Pindur, U.; Erfanian-Abdoust, H. $[4+2]$ Cycloadditions of Pyrano[3,4- $b$ ] Indol-3-ones with 1,2-bis-Acceptor Substituted Ethenes: First Evidence for a Non-Concerted Dields-Alder Step. Heterocycles 1990, 31, 1751-1761.

3. Gribble G. W. In The Alkaloids, Vol. 39; Brossi, A., Ed.; Academic Press: New York, 1990; p 239.

4. Powers, J. C. The Mass Spectrometry of Simple Indoles. J. Org. Chem. 1968, 33, 2044-2050.

5. Marx, M.; Djerassi, C. Mass Spectrometry in Structural and Stereochemical Problems. CXLIX. The Question of Ring Expansion in the Fragmentation of ${ }^{13} \mathrm{C}$-Labeled Nitrogen Heterocycles. J. Am. Chem. Soc. 1968, 90, 678-681.

6. Corval, M. Elimination sous Impact Electronique de HCN and $\mathrm{H}^{\prime}$ a partir de l'Indole. Comparison avec l'Indolizine. Org. Mass Spectrom. 1979, 14, 213-219. 
7. Corval, M. An Electron Impact Study of HCN Elimination from Indole by Use of ${ }^{13} \mathrm{C}$ Labeling. Org. Mass Spectrom. 1981, $16,444-447$.

8. Rodriguez, J. G.; Canoira, L. Electron Impact Mass Spectrometry of Indoline Derivatives. Int. J. Mass Spectrom. Ion Processes 1995, 142, 23-29.

9. Rodriguez, J. G.; Urrutia, A.; Canoira, L. Electron Impact Mass Spectrometry of Indole Derivatives. Int. J. Mass Spectrom. Ion Processes 1996, 152, 97-110.

10. Erra-Balsells, R. Mass Spectral Fragmentation Patterns of 2-Methyl-, 3-Methyl-, 2,3-Dimethyl-, 2-Aryl-, and 3-Phenylindole Derivatives. J. Heterocyclic Chem. 1987, 24, 1117-1120.

11. Erra-Balsells, R. Mass Spectral Fragmentation Patterns of 2,3-Diphenylindole Derivatives and Dibenzo[ac]Carbazoles. J. Heterocyclic Chem. 1988, 25, 221-224.

12. Porter, Q. N. In Mass Spectrometry of Heterocyclic Compounds, 2nd ed.; J. Wiley and Sons: New York, 1985; pp 555-580 and references cited therein.

13. Giorgi, G.; Ponticelli, F.; Czira, G.; Vékey, K. Characterization and Differentiation of Heterocyclic Isomers. Tandem Mass Spectrometry and Molecular Orbital Calculations on 3-Methylisoxazolo- and 2-Methyloxazolo-Pyridines. J. Am. Soc. Mass Spectrom. 1995, 6, 962-971.

14. Giorgi, G.; Anzini, M.; Cappelli, A.; Corelli, F.; Vomero, S. Characterization and Differentiation of Heterocyclic Isomers. Part 2. Mass Spectrometry and Molecular Orbital Calculations on Pyrrolo [1,2-a][1,4] Benzodiazepin-4-one, -6-one, -4,6-dione. J. Am. Soc. Mass Spectrom. 1996, 7, 653-663.

15. Giorgi, G.; Salvini, L.; Ponticelli, F. Structural Characterization and Regiochemical Differentiation of Modified Isomeric Tryptophans. J. Am. Soc. Mass Spectrom. 2002, 13, 1298-1303.

16. Giorgi, G.; Salvini, L.; Ponticelli, F. Gas Phase Reactivity of Isomeric Arylglycosides Towards Amines. A Chemical Ioniza- tion Mass Spectrometry and Tandem Mass Spectrometry Study. J. Am. Soc. Mass Spectrom. 2004, 15, 244-252.

17. Donati, D.; Fusi, S.; Ponticelli, F.; Roncucci, G. Photochemical $\alpha$-Cyanoethylation of Indoles. Gazz. Chim. Ital. 1994, 124, 71-76.

18. Frisch, M. J.; Trucks, G. W.; Schlegel, H. B.; Scuseria, G. E.; Robb, M. A.; Cheeseman, J. R.; Zakrzewski, V. G.; Montgomery, J. A., Jr.; Stratmann, R. E.; Burant, J. C.; Dapprich, S.; Millam, J. M.; Daniels, A. D.; Kudin, K. N.; Strain, M. C.; Farkas, O.; Tomasi, J.; Barone, V.; Cossi, M.; Cammi, R.; Mennucci, B.; Pomelli, C.; Adamo, C.; Clifford, S.; Ochterski, J.; Petersson, G. A.; Ayala, P. Y.; Cui, Q.; Morokuma, K.; Rega, N.; Salvador, P.; Dannenberg, J. J.; Malick, D. K.; Rabuck, A. D.; Raghavachari, K.; Foresman, J. B.; Cioslowski, J.; Ortiz, J. V.; Baboul, A. G.; Stefanov, B. B.; Liu, G.; Liashenko, A.; Piskorz, P.; Komaromi, I.; Gomperts, R.; Martin, R. L.; Fox, D. J.; Keith, T.; Al-Laham, M. A.; Peng, C. Y.; Nanayakkara, A.; Challacombe, M.; Gill, P. M. W.; Johnson, B.; Chen, W.; Wong, M. W.; Andres, J. L.; Gonzalez, C.; Head-Gordon, M.; Replogle, E. S.; Pople, J. A. Gaussian 98, Revision A.11.3; Gaussian, Inc.: Pittsburgh, PA, 2002.

19. Becke, A. D. Density-Functional Thermochemistry. III. The Role of Exact Exchange. J. Chem. Phys. 1993, 98, 5648-5652.

20. Beynon, J. H. In Mass Spectroscopy and Its Applications to Organic Chemistry; Elsevier: Amsterdam, 1960; p 397.

21. Cum, G.; Sindona, G.; Uccella, N. Effect of Substituent Group Interaction in the Fragmentation of Some Pyrrolidin-3-Ones. Org. Mass Spectrom. 1977, 12, 8-15.

22. Karni, M.; Mandelbaum, A. The "Even-electron Rule". Org. Mass Spectrom. 1980, 15, 53-64.

23. Stagno d'Alcontres, I.; Cum, G.; Uccella, N. Electron Impact Induced Rearrangement of Organic Ions. Part II. Unimolecular Decomposition of Some Isomeric $\mathrm{C}_{9} \mathrm{H}_{10} \mathrm{~N}^{+\cdot}$ Metastable Ions. Org. Mass Spectrom. 1973, 7, 1173-1177. 